\title{
INTER \\ A TRANSMISSÃO DO PATRIMÔNIO NA AGRICULTURA FAMILIAR: UMA ANÁLISE A PARTIR DA COMPENSAÇÃO DAS FILHAS
}

\section{THE PROPERTY TRANSMISSION IN THE FAMILY AGRICULTURE: AN ANALYSIS FROM THE DAUGHTER'S COMPENSATION}

\section{LA TRANSMISIÓN DEL PATRIMONIO EN LA AGRICULTURA FAMILIAR: UN ANÁLISIS A PARTIR DE LA COMPENSACIÓN DE LAS HIJAS}

\author{
Rosani Marisa Spanevello ${ }^{1}$ \\ Adriano Lago $^{2}$
}

\section{RESUMO:}

$\mathrm{Na}$ transmissão do patrimônio na agricultura familiar as formas de divisão e compensação são distintas entre filhos e filhas. Na grande maioria dos casos, são os filhos que ficam com o estabelecimento paterno. Com isso, os pais compensam as filhas de diferentes formas. O objetivo deste artigo é analisar a transmissão do patrimônio na agricultura familiar com foco nas formas de compensação das filhas. Para responder a questão proposta, foram entrevistados agricultores familiares dos municípios de Pinhal Grande e Dona Francisca, ambos localizados na região central do Rio Grande do Sul. Os resultados confirmam que as filhas não são expropriadas do recebimento do estabelecimento familiar apenas nos casos em que elas são filha única. Nos demais casos, os estabelecimentos tendem a ficar com um dos filhos homens - o sucessor -, enquanto as filhas recebem outras compensações: pagamento dos estudos, imóvel urbano, enxoval e dinheiro. Em muitas situações, as filhas recebem mais de uma forma de compensação.

Palavras - chaves: Transmissão do patrimônio. Filhas. Agricultura familiar.

\section{ABSTRACT:}

In the transmission of property in family agriculture, the division and the compensation forms are distinct between sons and daughters. In the majority of the cases, the sons earn the paternal establishment. This way, the fathers compensate the daughters in different ways. The goal of this article is to analyze the transmission of the property in the family agriculture with a focus on the daughter's compensation form. Answering the proposed issue, family farmers from the central region of Rio Grande do Sul, Pinhal Grande and

\footnotetext{
${ }^{1}$ Doutora em Desenvolvimento Rural, Profa . Adjunta do Departamento de Zootecnia do Centro de Educação Superior Norte (CESNORS) da Universidade Federal de Santa Maria (UFSM), área: Extensão e Sociologia Rural. Pesquisadora do Grupo de Pesquisas NEMAD. E-mail: rspanevello@yahoo.com.br

${ }^{2}$ Doutor em Agronegócios. Prof. Adjunto do Departamento de Agronomia do Centro de Educação Superior Norte (CESNORS), Campus Frederico Westphalen, Universidade Federal de Santa Maria (UFSM), áreas: Cooperativismo, relacionamentos interorganizacionais, agronegócio. Pesquisador do Grupo de Pesquisas NEMAD. E-mail: adrianolago@yahoo.com.br
}

R. Inter. Interdisc. INTERthesis, Florianópolis, v.7, n.1, p. 222-141, jan./jul. 2010 
Dona Francisca municipalities, were interviewed. The results confirm that the daughters are not excluded from the family establishment just in the cases when they are the only child. In the other cases, the establishments tend to remain with one of the sons - male successor - while the daughters receive other compensations: studies payment, urban real state, trousseau and money. In many situations, the daughters earn more than one compensation form.

Keywords: Property transmission. Daughters. Family agriculture.

\section{RESUMEN:}

En la transmisión del patrimonio en la agricultura familiar las formas de división y compensación son distintas entre hijos e hijas. En la gran mayoría de los casos, son los hijos que se quedan con el establecimiento paternal. Con eso, los padres remuneran sus hijas de diferentes formas. El objetivo de este artículo es analizar la transmisión del patrimonio en la agricultura con foco en las formas de remuneración de las hijas. Para responder a la cuestión fueron entrevistados agricultores familiares de las ciudades de Pinhal Grande y Dona Francisca, ambos ubicados en la región central de Rio Grande do Sul. Los resultados confirman que las hijas no son expropiadas del recibimiento del establecimiento familiar sólo en los casos en que ellas son hija única. En los demás casos, los establecimientos se quedan con uno de los hijos hombres - el sucesor - en cuanto las hijas reciben otras remuneraciones: pago de los estudios, casas urbanas, ajuar y dinero. En muchas situaciones, las hijas reciben más de una forma de remuneración.

Palabras clave: Transmisión del patrimonio. Hijas. Agricultura familiar.

\section{INTRODUÇÃO}

Considerando as populações rurais, especialmente os agricultores familiares, observa-se uma divisão no processo de reprodução social. De um lado, está a reprodução cotidiana ou diária; de outro, a reprodução das gerações futuras. Conforme Tedesco (1999), a reprodução dos agricultores está intimamente relacionada à produção e à reprodução dos estabelecimentos e dos indivíduos nela envolvidos.

A noção citada acima se aproxima da noção de reprodução social destacada por Almeida (1986). O autor faz uma revisão sobre os diferentes estudos ${ }^{3}$ realizados entre década de 1970 e 1980, especialmente no Sul e Nordeste brasileiro, e comprova a abordagem da reprodução sob dois enfoques. No primeiro, a reprodução anual ou de ciclo curto e, no segundo, a reprodução geracional ou de ciclo longo.

A reprodução de ciclo curto compreende a combinação de fatores relativos ao trabalho, conhecimento tradicional e recursos naturais para atender ao consumo familiar e

${ }^{3}$ Os principais estudos analisados pelo autor são: Brandão (1982); Garcia Jr; (1983); Heredia (1979); Moura (1978); Neves (1981); Santos (1978); Seyferth (1985) e Woortmann (1984).

R. Inter. Interdisc. INTERthesis, Florianópolis, v.7, n.1, p. 222-141, jan./jul. 2010 
repor os insumos necessários para o reinício do processo produtivo. De forma geral, o autor relaciona a reprodução de ciclo curto com a lógica econômica da família, englobando elementos como trabalho e consumo. Já a reprodução de ciclo longo envolve os aspectos do ciclo geracional e de como as famílias se perpetuam. A perspectiva de perpetuação da família é baseada em aspectos relacionados ao nascimento, casamento, morte e herança (ALMEIDA, 1986). Na reprodução de ciclo longo também podem ser acrescentadas as questões relativas à formação das novas gerações de agricultores, como a sucessão e a saída dos pais do comando do estabelecimento.

É dentro da dimensão da reprodução de longo prazo que se enquadra o presente artigo ao tratar do tema da transmissão do patrimônio entre os agricultores familiares. Na sua essência, a transmissão do patrimônio envolve a divisão dos bens ou a herança especialmente a terra - entre os filhos. Esse processo constitui-se em um dos movimentos básicos da reprodução na agricultura familiar (WOORTMANN, 1995), porque só tem direito ao patrimônio quem realmente faz parte da rede de relações familiares, pois ela é fruto direto do vínculo do parentesco (TEDESCO, 1999). Além disso, segundo Carneiro (2001), as formas de transmissão são múltiplas e variáveis de acordo com o contexto histórico, econômico e geográfico. Os arranjos também dependem das possibilidades de trabalho assalariado e das características da família (número e sexo dos filhos) (SEYFERTH, 1985).

Tradicionalmente, uma das especificidades mais marcantes do processo de divisão do patrimônio familiar é dar a terra aos filhos homens, especialmente ao (s) sucessor (es) e recompensar as filhas com outros bens, principalmente com o enxoval, por ocasião do casamento. Esse padrão era imposto pelos pais e aceito pelos filhos e filhas como necessário para a continuidade da reprodução social do grupo familiar.

Mais recentemente, em razão dos problemas sucessórios que cercam a agricultura familiar, tais como: a desistência de muitos filhos e, principalmente das filhas, em seguir na ocupação paterna e estabelecer casamentos com filhos de agricultores; a demorada espera pela vontade paterna para transmitir o estabelecimento e; os próprios questionamentos em torno das formas da divisão propostas pelos pais dão uma nova dimensão à transmissão do patrimônio, com destaque para as formas de divisão e compensação das filhas. Considerando a situação específica das mulheres, a discussão envolve a possibilidade das mesmas serem ou não sucessoras e os bens ou

R. Inter. Interdisc. INTERthesis, Florianópolis, v.7, n.1, p. 222-141, jan./jul. 2010 
compensações patrimoniais que cabem a elas atualmente quando thes é negado à sucessão do estabelecimento.

Com base na dimensão exposta acima, o presente artigo discute os arranjos ou encaminhamentos em torno da transmissão do patrimônio elaborados pelos agricultores familiares, com foco nas diferentes formas de divisão e compensação dada às filhas.

Na composição do artigo, apresenta-se: Procedimentos metodológicos; Revisão bibliográfica sobre agricultura familiar; Revisão bibliográfica sobre as especificidades da transmissão do patrimônio na agricultura familiar, Análise das formas de divisão e compensação do patrimônio familiar das filhas com base na pesquisa realizada e considerações finais.

\section{PROCEDIMENTOS METODOLÓGICOS}

A pesquisa é do tipo qualitativa e foi desenvolvida no primeiro trimestre de 2007, nos municípios de Pinhal Grande e Dona Francisca, ambos pertencentes à Quarta Colônia de Imigração Italiana - localizada da Região Central do Rio Grande do Sul. A escolha dos dois municípios - entre os nove que compõem a Quarta Colônia - teve como principal critério à representatividade da agricultura familiar.

Quanto a seleção dos agricultores, foram considerados os seguintes aspectos: 1) Ter pelo menos um (a) filho (a), independentemente do sexo; 2) Ter 50 anos ou mais. Esse recorte etário se justifica pelo fato da pesquisa centrar-se em situações de transmissão de patrimônio definida ou encaminhada, tendo em vista que a literatura aponta que, na agricultura familiar, a transmissão do patrimônio é um processo tardio, ou seja, os pais encaminham ou realizam a transmissão do patrimônio quando atingem idade mais avançada. Com isso, foi necessário estabelecer um recorte etário para evitar o risco de entrevistarmos agricultores jovens ou recém-estabelecidos ou mesmo com filhos pequenos, o que não permitiria tratarmos do tema da transmissão do patrimônio. Neste sentido, a exemplo do trabalho realizado por Champagne (1986a, b), optou-se por entrevistar agricultores acima de 50 anos.

No total foram entrevistados 26 agricultores familiares com sucessão, ou seja, agricultores que apresentam a perspectiva de ter um filho disposto a permanecer no estabelecimento para dar continuidade. Além dos agricultores - chefes dos

R. Inter. Interdisc. INTERthesis, Florianópolis, v.7, n.1, p. 222-141, jan./jul. 2010 
estabelecimentos -, foram entrevistadas as esposas e em alguns casos também as filhas. Os principais questionamentos fazem referência a quem fica com o estabelecimento e a forma de divisão do patrimônio entre os filhos (sucessores e não sucessores), considerando mais especificamente a situação das filhas.

\section{A DINÂMICA DA TRANSMISSÃO DO PATRIMÔNIO NA AGRICULTURA FAMILIAR}

\subsection{Agricultura Familiar}

No Brasil, o debate e o crescente fomento à agricultura familiar ganharam visibilidade política e social na década de 1990, com a implantação do Programa Nacional de Fortalecimento da Agricultura Familiar - PRONAF. Este é um programa de políticas públicas específicas para os agricultores familiares iniciado em 1995, pela pressão política dos Sindicatos dos Trabalhadores Rurais e demais movimentos sociais ligadas ao campo, como a Confederação Nacional dos Trabalhadores da Agricultura - CONTAG.

A implantação do PRONAF demarca, pela primeira vez no país, a destinação de recursos econômicos financiados pelo Estado para os agricultores enquadrados ${ }^{4}$ nesse segmento, com o intuito de fortalecer a produção agrícola e a viabilidade econômica. Além desse objetivo, o PRONAF trouxe o reconhecimento social de uma "nova" categoria ${ }^{5}$ no meio rural brasileiro: agricultor familiar.

Na caracterização e conceituação do termo agricultura familiar Abramovay (1998), considera três atributos importantes: gestão, propriedade e trabalho familiar proveniente de indivíduos que mantêm entre si laços de sangue ou de casamento.

Na concepção de Wanderley (2001), a agricultura familiar é entendida como aquela em que a família, ao mesmo tempo em que é proprietária dos meios de produção (produzindo para seu consumo e para o mercado), assume o trabalho no estabelecimento produtivo. A conjugação dessas características, ou seja, o fato de uma estrutura produtiva associar família-produção-trabalho tem conseqüências fundamentais na forma como ela

\footnotetext{
${ }^{4}$ O PRONAF Crédito Rural financia atividades agropecuárias, pesca, aqüicultura, extrativismo e atividades não-agrícolas, como o artesanato e turismo rural. O público beneficiário são agricultores familiares, pescadores, silvicultores, indígenas, quilombolas, aqüicultores, extrativistas entre outros. As formas de acesso podem ser individual ou coletiva (BRASIL, 2008).

${ }^{5}$ A noção de camponês e agricultor familiar tem permeado vários debates entre os estudiosos do tema. A questão central diz respeito ao fato do agricultor familiar ser o "antigo" camponês, ou o agricultor familiar ser uma nova categoria criada a partir da intensificação do capitalismo na agricultura. Para maior aprofundamento consultar os trabalhos Wanderley (2001) e Abramovay (1992).
}

R. Inter. Interdisc. INTERthesis, Florianópolis, v.7, n.1, p. 222-141, jan./jul. 2010 
age econômica e socialmente. Uma das conseqüências dessa forma de agir é atender às necessidades do grupo doméstico e à reprodução das gerações subseqüentes. Conforme Wanderley (2001, p. 24), através da conjugação desses dois objetivos, resultam as características fundamentais da agricultura familiar, "a especificidade do processo, seu sistema de produção e a centralidade da constituição do patrimônio familiar".

O trabalho de Gasson e Errington (1993) desenvolve uma definição mais detalhada sobre a agricultura familiar, conciliando as relações entre o estabelecimento ou a propriedade e o grupo doméstico, e as características existentes dos estabelecimentos atualmente, tanto as de cunho mais empresarial como as familiares. O estudo define as características, levando em conta fatores como a natureza da própria ocupação, do trabalho dos membros e a combinação entre a administração e controle dos negócios do estabelecimento, além do processo de sucessão. No total, são definidas seis características: a) A gestão encontra-se nas mãos dos proprietários dos estabelecimentos; b) Os proprietários do empreendimento estão ligados entre si por laços de parentesco; c) É responsabilidade de todos os membros da família prover capital para o empreendimento; d) $O$ trabalho é feito pela família; e) $O$ patrimônio e a gestão do estabelecimento são repassados de geração a geração; f) Os membros da família vivem no estabelecimento.

$\mathrm{Na}$ tentativa de caracterizar a agricultura familiar dentro da economia capitalista, Friedmann (1986), citada por Gasson e Errington (1993, p. 17), dá maior ênfase às relações internas entre os membros da família, ao afirmar existirem duas questões específicas dos agricultores familiares. A primeira trata da organização da produção através das relações de parentesco com uma divisão do trabalho por sexo e idade, tendo em vista a realização do trabalho pelos próprios membros familiares, enquanto nos estabelecimentos de produção capitalista, o trabalho é realizado por pessoas contratadas. A segunda trata da combinação entre propriedade e trabalho, pois o trabalhado e o dono dos meios de produção são as mesmas pessoas, enquanto a premissa capitalista prevê a separação entre propriedade e trabalho.

R. Inter. Interdisc. INTERthesis, Florianópolis, v.7, n.1, p. 222-141, jan./jul. 2010 


\subsection{Transmissão Desigual do Patrimônio}

No Brasil, os estudos ${ }^{6}$ mostram que o Código Civil (2002) garante o direito igualitário à herança a todos os filhos denominados herdeiros legítimos ou naturais. No entanto, na Região Sul do Brasil, os descendentes de italianos desconsideram as normas do Código Civil e fazem predominar tradições costumeiras na transmissão do patrimônio em detrimento das determinações legais ou da lei (CARNEIRO, 2001; DEERE e LEÓN, 2002; PAULILO, 2004; WOORTMANN, 1995). Isso equivale a dizer que as regras culturais (costumeiras) adotadas pelos agricultores se sobrepõem as regidas pela lei do Código Civil no momento da divisão do patrimônio. Como resultado, a divisão não é igualitária ${ }^{7}$ entre os filhos.

$\mathrm{Na}$ transmissão do patrimônio, o pai é reconhecido pelos demais membros da família como a figura central, porque é ele quem determina a divisão dos bens entre os seus descendentes. Conforme Tedesco (1999, p. 107), "o direito de decisão sobre a partilha é atribuição exclusiva do esposo (pai)". Os arranjos propostos pelo pai são entendidos pelos demais como regras que visam sustentar a família de forma simbólica e econômica, garantindo a manutenção de um filho na terra e a perpetuação do patrimônio ao longo das gerações; e a reprodução econômica da família agricultora através da viabilidade produtiva do estabelecimento. Na Região Sul do Brasil, esse predomínio paterno tem como costume privilegiar um único filho como sucessor do estabelecimento familiar. Nessas condições, o estabelecimento fica com o sucessor e os demais filhos e filhas recebem outras formas de compensação, caracterizando a divisão desigual.

Para compreender a transmissão desigual do patrimônio é preciso levar em conta os distintos papéis reservados aos homens e as mulheres na dinâmica de reprodução social (CARNEIRO, 2001).

É a divisão no trabalho que fundamenta a forma de divisão do patrimônio e o que cabe aos filhos e às filhas. A divisão por sexo é uma das formas mais recorrentes de divisão do trabalho entre os agricultores familiares, ou seja, a socialização dos filhos no trabalho é marcada pela divisão das atividades entre homens e mulheres. O processo de

\footnotetext{
${ }_{7}^{6}$ Carneiro (2001), Woortmann (1995).

${ }^{7}$ Ao fazerem uso desse artifício, os agricultores evitam o fracionamento excessivo, mantendo a integridade do patrimônio e a sua reprodução econômica, mas também a reprodução de uma identidade social sustentada na propriedade fundiária e no trabalho agrícola (CARNEIRO, 2001).
}

R. Inter. Interdisc. INTERthesis, Florianópolis, v.7, n.1, p. 222-141, jan./jul. 2010 
socialização estimula os filhos a exercerem futuramente trabalhos distintos: os meninos trabalham junto com os irmãos e o pai nas atividades agrícolas e nas posições de comando para que, futuramente, se tornem chefes de famílias, enquanto as meninas são incorporadas aos trabalhos de casa ou domésticos, do quintal e no cuidado dos irmãos menores, supervisionadas pelas mães ou irmãs mais velhas (MARIN, 2005). Assim, enquanto os rapazes tornam-se conhecedores das técnicas e da produção agrícola, as moças conhecem o "serviço da casa" ou doméstico, como resultado de uma socialização que permite aos filhos obter conhecimentos específicos dos papéis determinados pela divisão sexual do trabalho (SANTOS, 1984).

O resultado da divisão sexual do trabalho na agricultura é o não reconhecido do trabalho feminino como produtivo ou com valor econômico. De acordo com Woortmann (1995, p. 35), a divisão do trabalho demarca uma oposição ideológica entre o trabalho da casa ou doméstico, do trabalho na lavoura ou agrícola, "é como se houvesse um trabalho parcial produtivo (desde o ponto da vista do economista) e outro "não produtivo" (as atividades realizadas em casa)". Desse modo, segundo Carneiro (2001), o trabalho familiar é dividido em duas categorias: "ajuda" (as atividades desempenhadas pela mulher e pelos jovens) e "trabalho" (as atividades masculinas na lavoura), usualmente empregada no meio rural brasileiro. Ao homem (pai e filhos) cabe o espaço da produção e das relações externas; a mulher (mãe e filhas) o espaço da casa e do consumo. O que os homens fazem, tanto pode ser usado como insumo interno ou mercadoria, já o que mulheres fazem tem apenas uso doméstico (CARNEIRO, 2001; WOORTMANN e WOORTMANN, 1997).

Por trás do significado da noção "ajuda" reside à invisibilidade do trabalho agrícola feminino nos estabelecimentos familiares, geralmente considerado um trabalho secundário, seja pelo tipo e intensidade do trabalho desenvolvido na lavoura, seja por assumirem praticamente sozinhas o trabalho doméstico (DEERE; LEÓN, 2002). A noção ou o significado do papel de ajudante é fundamentalmente trabalhar conforme a demanda das atividades, geralmente sem envolvimento nos processos de tomada de decisões do trabalho agrícola (GASSON; ERRINGTON, 1993). Por isso, a terra deve ficar com quem efetivamente trabalha nela. Nesse caso, deve ficar com os homens que desempenham as atividades relacionadas à produção agrícola (DEERE; LEÓN, 2002).

R. Inter. Interdisc. INTERthesis, Florianópolis, v.7, n.1, p. 222-141, jan./jul. 2010 
Considerando o que recebem as filhas na transmissão e divisão do patrimônio, observa-se que as variações dos bens a serem recebidos por elas dependem, principalmente, da sua permanência no meio rural e da concretização do casamento com um agricultor, da sua saída para estudar no meio urbano e dos recursos econômicos da família.

Pelas regras costumeiras, as filhas que permanecem no meio rural e se casam com um agricultor ganham um enxoval composto de roupas de cama, mesa e banho, utensílios domésticos e, por vezes, máquina de costura e vaca leiteira, podendo ter mais ou menos itens, conforme as posses dos pais (CARNEIRO 2001; PAULILO, 2004; SANTOS, 1984). Além do enxoval, as mulheres também podem receber terras, geralmente em menor quantidade que o sucessor, podendo ser uma parte do estabelecimento ou mesmo fora dele, mas geralmente não cultivam e, por isso, podem efetuar posteriormente a venda para o irmão que acaba reincorporando novamente a área original do pai, após os acertos da transmissão. Desse modo, ainda que os arranjos realizados pelos agricultores garantam o direito das filhas a receber terras, o acesso a estas e seu uso para o cultivo dificilmente são concretizados, porque geralmente elas ficam pendentes "moralmente" de vendê-las para o irmão sucessor (WOORTMANN, 1995).

Por outro lado, as mulheres que permanecem no meio rural sem casar, nada recebem. O destino das celibatárias, segundo Paulilo (2004, p. 234) - "cuidar dos pais e, depois de sua morte, ficar "encostada" na casa de uma irmã ou cunhada, ajudando nos afazeres domésticos - não é invejado por ninguém".

Outra prática é substituir a terra por valor monetário; o pai substitui a terra (muitas vezes dada a um irmão) que por direito é da filha, pelo valor corresponde em dinheiro (WOORTMANN, 1995). Além dessas práticas, a recompensa em terra pode ser revertida em sua manutenção na cidade enquanto estudam e se preparam para a inserção no mercado de trabalho urbano (CARNEIRO, 2001). A associação entre uma ou outra prática (tais como o pagamento dos custos dos estudos ou doação de imóveis urbanos) também depende das condições econômicas dos pais e do patrimônio que podem ou pretendem deixar para as filhas.

Além das distintas formas de compensação, Paulilo (2004) chama a atenção sobre o significado da doação feita às filhas (e aos filhos) quando saem do estabelecimento

R. Inter. Interdisc. INTERthesis, Florianópolis, v.7, n.1, p. 222-141, jan./jul. 2010 
familiar para estudar e/ou trabalhar na cidade. Nesses casos, os filhos homens não recebem terras, mas dinheiro ou imóvel que representam uma forma de remuneração pelo esforço investido junto com os demais membros do grupo doméstico para aumentar o patrimônio e não como herança. Os agricultores efetuam um "pagamento" pelo trabalho agrícola realizado pelos filhos até o momento da sua saída. No caso das filhas - cujo trabalho agrícola exercido por elas tem o caráter de ajuda -, não há o que lhes "pagar". O enxoval é geralmente adquirido por elas com o salário recebido pelo trabalho urbano ao invés de ser dado pelos pais como "pagamento" pelo trabalho realizado no estabelecimento familiar até a sua saída (PAULILO, 2004).

Os casos em que as mulheres recebem ou tem acesso a terra, de acordo com Paulilo (2004), é quando não há descendência masculina; quando há uma filha casada que cuida dos pais na velhice; quando os pais possuem muita terra (PAULILO, 2004). Em casos em que não há filhos homens, a única opção dos pais se resume em deixar o patrimônio com a (s) única (s) herdeira (s). Outra forma das filhas terem acesso a terra ocorre em casos em que amparam os pais na velhice e ficam responsáveis pela sua manutenção, cuidados médicos, assumindo as eventuais despesas. Nessas condições, os pais entendem que devem deixar o patrimônio (ou parte dele) para a filha que se dedica aos seus cuidados. A terra funciona como um "pagamento" pelo tempo gasto no cuidado dos pais e pelas eventuais despesas monetárias que a filha venha a ter com eles durante a velhice.

Também podem estar sujeitas a receberem terras, as filhas de agricultores familiares com áreas suficientes para instalar todos os filhos homens, seja através de compras de novas áreas ou de novas propriedades. Nesses casos, as filhas, além do enxoval, podem receber um pedaço de terra. Essa condição é geralmente encontrada entre agricultores que dispõem de uma melhor condição em termos de capital financeiro.

Carneiro (2001) salienta existir outra situação em que as filhas recebem como patrimônio (terra) de forma igualitária. Segundo a autora, quando a terra é considerada uma mercadoria - não representando o meio ou o único meio de sustento da família porque os membros exercem outra atividade ou porque é inviável para a agricultura -, é que as mulheres são incorporadas na herança da terra.

Quando a terra não simboliza a linha de ascendência e perdeu seu valor como meio de produção, a preservação da propriedade deixa de ter sentido, e passa a ser uma questão resolvida pelos indivíduos e não pela família. Neste contexto,

R. Inter. Interdisc. INTERthesis, Florianópolis, v.7, n.1, p. 222-141, jan./jul. 2010 
entende-se a partilha generalizada: a mulher herda uma parcela de terra já destituída de valor econômico (porque é inviável para a agricultura) e de valor simbólico (porque não é atribuído de identidade social) (CARNEIRO, 2001, p.47)

\section{O PATRIMÔNIO DAS FILHAS}

Através dos dados da pesquisa de campo nos dois municípios já citados, na região da Quarta Colônia de Imigração Italiana, é possível delimitar um quadro sobre os acertos ou encaminhamentos em torno da transmissão do patrimônio familiar relativo às filhas.

Em primeiro lugar, o que a pesquisa de campo nos permite observar, é que a transferência e os arranjos em relação ao patrimônio, tanto das filhas como dos filhos, são construídos ao longo da vida dos agricultores. Os encaminhamentos dados pelos pais iniciam através do apoio dos estudos para as filhas, pela compra de uma área de terra para os demais filhos ou para o filho sucessor, entre outros. Por isso, os agricultores afirmam que não há um momento demarcado para resolver essa questão e tendem a estendê-lo "mais para frente", configurando um processo de transmissão tardia.

A explicação disso é que os pais podem ser considerados uma força de trabalho ativa no estabelecimento. É o esgotamento da força física que demarca a retirada dos agricultores (pais) do trabalho e do controle do estabelecimento. Conforme Carneiro (1998) ser o chefe do estabelecimento familiar é ter assegurado a condição de proprietário e o pai tenta ao máximo retardar a transferência da posse da terra na tentativa de assegurar sua autoridade e a garantia de ser cuidado pelo filho sucessor.

Ao decidir realizar a transferência e a divisão do patrimônio, duas questões centrais podem ser destacadas: 1) O estabelecimento pertence a um dos filhos homens sucessor; 2) As filhas são recompensadas de outras formas. Em alguns casos, se mantêm a não compensação das filhas com terra, enquanto em outros o enxoval ou mesmo a terra é substituído por um valor em dinheiro.

A transferência para apenas um filho - o sucessor - é justificada de diferentes maneiras pelos entrevistados: pelo fato do sucessor ter que cuidar dos pais, por sempre ter trabalhado na agricultura enquanto os demais filhos estudaram, entre outras. Nesse sentido, ao repassar o estabelecimento para o sucessor, os agricultores, além de instalar o filho na atividade agrícola e garantir a ele o seu sustento através dessa atividade, também acionam elementos da ordem moral através da tentativa de garantir que o

R. Inter. Interdisc. INTERthesis, Florianópolis, v.7, n.1, p. 222-141, jan./jul. 2010 
sucessor os ampare na velhice. Entre as formas usadas para garantir a instalação dos seus sucessores pode-se citar: a subdivisão de uma parte da área do estabelecimento familiar, proporcional ao tamanho da área ou o repasse de uma área de terra, fora do estabelecimento para garantir que o sucessor casado se instale separadamente.

Se o estabelecimento fica com o sucessor, entra em cena a compensação das filhas, reafirmando uma divisão desigual. A divisão é um processo pensado em relação ao sucessor, tendo em vista que ele é o responsável pela manutenção do estabelecimento, mas também em função da ocupação atual das filhas.

As situações de divisão relatadas pelos agricultores e a situação das filhas podem ser visualizadas nas distintas situações descritas abaixo:

\section{1) Filhas recebem pagamentos dos estudos e terra}

Esses arranjos são encontrados nos estabelecimentos em que há apenas um filho homem e os demais são mulheres. Enquanto o filho fica com o estabelecimento, as filhas que saíram para estudar receberam o pagamento dos estudos, mas também receberão alguma área de terra. Prevalecem aqui os arranjos costumeiros, que atribui à maior parte da terra ou o estabelecimento para quem efetivamente trabalha nela: neste caso, o filho homem.

Por outro lado, por se tratar de agricultores mais capitalizados, esses arranjos prevêem que além do estudo, as filhas recebam parte em terra, mesmo sendo em quantidade menor que o sucessor. No entanto, a terra dada às filhas apresenta uma conotação simbólica, pois fica claro no depoimento dos agricultores, que as filhas, dificilmente irão desenvolver atividade agrícola sobre a área, em razão da possibilidade de venda para os irmãos sucessores. Essa pendência moral de venda ao irmão sucessor, conforme ressalta Woortmann (1995) pode ser visualizada de forma mais clara no depoimento dos entrevistados:

\footnotetext{
Para as meninas eu vou deixar um pouco de terra, eu até gostaria de deixar um pouco mais, por enquanto vou dividir assim: uma parte para mim, uma parte para as gurias e a propriedade fica para o M., que pode ficar com a parte das gurias um dia, comprando delas (Agricultor 5).
}

O J. pode comprar a parte das gurias depois, para ficar com toda a área (Agricultor 3).

R. Inter. Interdisc. INTERthesis, Florianópolis, v.7, n.1, p. 222-141, jan./jul. 2010 


\section{2) As filhas recebem imóvel na cidade}

Os agricultores que apresentam esse arranjo, afirmam que as filhas, em razão dos empregos urbanos, residem na cidade e não precisam da terra. É o filho sucessor quem vai viver da atividade agrícola, portanto, o estabelecimento deve ficar com ele.

Um das razões expostas pelos agricultores para realizar a transmissão do patrimônio é o reduzido tamanho do estabelecimento que não permite subdividir sem inviabilizar economicamente. Nessas condições, os pais excluem as filhas da possibilidade de herdar o estabelecimento, usando como justificativa o tamanho da área.

Apesar da possibilidade da filha abandonar os estudos e retornar ao meio rural e se instalar como agricultora, a prioridade para o pai é deixar o estabelecimento para o filho homem, até porque espera que a filha se case com um agricultor e vá residir no estabelecimento do marido. Nesse caso, os arranjos propostos pelo pai parecem estar em acordo com a vontade da filha, conforme se comprova em seu depoimento: "A terra é do meu irmão, eu espero casar com um agricultor e vou morar na terra dele, se isso não acontecer eu tenho a casa na cidade (Filha - Agricultor 19).

\section{3) Filhas ganham estudo}

O estudo é citado pelos agricultores como a forma de recompensa para as filhas, ou seja, a herança se resume ao pagamento dos estudos para ingressar no mercado de trabalho urbano. Conforme um dos entrevistados: "A gente está pagando a faculdade particular, o aluguel do apartamento, então acho que elas vão receber isso", pois pretendem deixar a terra "para quem precisa dela" ou para o sucessor (Agricultor 8).

Considerando a situação dos demais filhos homens não sucessores, os mesmos receberão terra (fora do estabelecimento familiar) em razão de não terem estudado, nem trabalhado em empregos urbanos ou atividades não-agrícolas.

\section{4) Filhas recebem enxoval e área de terra dentro ou fora do estabelecimento}

Nessa situação, as filhas são casadas com agricultores e tem o direito a terra (apesar de no momento do casamento, também terem recebido um enxoval) da mesma forma que os demais irmãos não sucessores, embora todos possam vir a receber menos

R. Inter. Interdisc. INTERthesis, Florianópolis, v.7, n.1, p. 222-141, jan./jul. 2010 
do que o sucessor. O sucessor herda o estabelecimento ou parte dele. O acesso a terra pelas filhas pode ser tanto parte do estabelecimento ou outra área em local distinto.

Conforme Woortmann (1995) apesar das mulheres, além do enxoval, terem direito a terra, na prática, a terra fica sob o domínio do marido, que pode futuramente negociar com o próprio cunhado (o sucessor) a venda da área dada como herança para a esposa, caso tenha recebido uma parte do estabelecimento e o cunhado tenha interesse em reincorporar novamente a área subdividida pelos acertos do patrimônio. Nesse caso, como diz Woortmann (1995, p. 194), "a herança não chega às mãos da mulher, mas constitui-se uma circulação entre os homens, onde a mulher é um elemento de cálculo, de intermediação".

Essa situação descrita acima é semelhante à encontrada na primeira descrição Filhas recebem pagamentos dos estudos e alguma terra, mas os sucessores são os homens. A diferença é que na primeira situação descrita, as filhas são solteiras e elas mesmas podem negociar com o irmão, enquanto na situação presente as filhas são casadas e a negociação da sua área de terra tende a ser feita pelo marido. $\mathrm{O}$ que as duas situações têm em comum é a escassa perspectiva de a terra ser de domínio das filhas. Além disso, caso as filhas descritas na primeira situação vierem a contrair matrimônio, provavelmente o processo de negociação das áreas será entre o marido e o irmão sucessor.

\section{5) Filhas recebem estudo e dinheiro}

As filhas recebem o pagamento dos estudos e também dinheiro. O dinheiro é usado para compensar o não recebimento do enxoval e da terra.

Com relação a terra, embora o estabelecimento seja do filho sucessor, os agricultores consideram que, além de estudo, as filhas também têm direito a algum pedaço de área. No entanto, desconsideram a possibilidade de subdividir o estabelecimento ou dar outra área de terra para as filhas. Os acertos previstos são: reverter o valor da terra em dinheiro.

Eu acho que as mulheres têm direito também, mas dar em terra seria difícil. A minha idéia é dar uma partezinha para as duas, então eu penso que posso dar assim [...] uma partezinha em dinheiro no lugar da terra (Agricultor 15).

R. Inter. Interdisc. INTERthesis, Florianópolis, v.7, n.1, p. 222-141, jan./jul. 2010 
Nesse caso, as filhas recebem "simbolicamente" o patrimônio como se fosse uma parte da terra. É contabilizado o valor da terra e o que as filhas recebem é um montante em dinheiro. Essa forma de divisão é justificada pelos agricultores em razão das filhas estarem estudando e não necessitarem da terra para tirar o seu sustento, enquanto o sucessor precisa de todo o estabelecimento para continuar produzindo. A parcela dada às filhas é minimizada pelo pai, que a chama de "partezinha".

Ao remunerar com dinheiro, os agricultores evitam a fragmentação da área. Além disso, evitam a necessidade da negociação futura entre os irmãos para a recomposição da área: "Porque depois ele ainda tem que negociar com as irmãs para comprar de volta, assim não precisa" (Esposa - Agricultor 15).

Os demais filhos recebem áreas de terras geralmente em outros locais, tendo em vista a indivisibilidade do estabelecimento paterno. Os agricultores cogitam a possibilidade de comprar áreas de terras para os filhos não sucessores, tanto dentro como fora do município, sempre tentando dar aos filhos "um pedaço de terra boa", em outros termos, terra para trabalhar com maquinário.

Além do "pagamento" pela terra, os arranjos propostos pelos agricultores, em "pagar" o enxoval para as filhas, constitui uma questão interessante para a análise. A substituição do enxoval - geralmente o único bem material dado às filhas por ocasião do seu casamento e saída do estabelecimento paterno -, por dinheiro, está estreitamente relacionado com o processo atual de saída dos jovens do meio rural, especialmente as mulheres. Estudos indicam que as moças ao saírem para estudar dificilmente regressam para a casa paterna para morar ou viver no meio rural. Ao buscarem os estudos, também recusam a possibilidade de casamento com os filhos de agricultores porque isso representa a continuidade no meio rural, na agricultura e na condição subalterna vivida pelas mães (STROPASOLAS, 2002; 2004). Se não há casamentos, mudam também as formas de compensação das mulheres quanto ao patrimônio.

\footnotetext{
A minha filha dificilmente vai voltar e se não volta, não casa com um agricultor, então essa história de enxoval caiu de moda, a gente pensa em recompensar em dinheiro (Agricultor 21).
}

A recompensa através do enxoval ou dos utensílios domésticos dados por ocasião do casamento dá lugar à recompensa baseada em uma quantia em dinheiro.

R. Inter. Interdisc. INTERthesis, Florianópolis, v.7, n.1, p. 222-141, jan./jul. 2010 
Para as filhas, serem recompensadas em estudo (principalmente quando os pais pagam por seus estudos em universidades particulares, despesas de moradia, transporte, vestuário) e dinheiro no lugar do enxoval e da terra, pode representar o recebimento de um patrimônio mais significativo monetariamente. Isso se deve ao fato do enxoval estar mais relacionado a uma compensação simbólica do que econômica (geralmente constituído de uma máquina de costura, peças de roupas e uma vaca leiteira), considerado de pouco valor comparativamente ao valor econômico da terra recebida pelos filhos. A mesma lógica vale para as áreas de terras geralmente recebidas pelas mulheres: menores quando comparadas com os irmãos, distantes, acidentadas geograficamente ou com problemas de erosão e fertilidade. Assim, receber o pagamento dos estudos e dinheiro pelo enxoval e pela terra que teriam direito pode representar um valor patrimonial superior ao que recebiam as gerações passadas, especialmente porque o principal bem a ser recebido era o enxoval.

\section{6) Filhas herdam o estabelecimento}

Nesse caso, os agricultores não podem contar com um filho varão para herdar o estabelecimento. As filhas têm direito a terra porque não tem irmãos, ou seja, são filhas únicas.

\section{CONSIDERAÇÕES FINAIS}

A reprodução social de longo prazo da agricultura familiar, considerando as questões relativas a transmissão do patrimônio, tem como característica a predominância das regras costumeiras e não as normas previstas pelo Código Civil. Dentro dessa lógica, verifica-se a predominância dos filhos homens como sucessores nos estabelecimentos, ou seja, o principal patrimônio dos agricultores, a terra, fica com a descendência masculina. Outra especificidade desse processo está centrada na tentativa de garantir integridade do estabelecimento e a capacidade de reprodução de uma família. Por isso, geralmente o estabelecimento é transmitido unicamente para aquele escolhido como sucessor.

R. Inter. Interdisc. INTERthesis, Florianópolis, v.7, n.1, p. 222-141, jan./jul. 2010 
Quanto ao patrimônio das filhas, em razão do não recebimento da terra, as formas de compensação são variadas, podendo existir mais de uma. As principais formas encontradas são as compensações em estudo, dinheiro, imóveis urbanos e enxoval.

Apesar do reconhecimento dos pais, em alguns casos, que as filhas têm direito a terra, o mesmo não acontece. Observa-se que os pais usam diferentes estratégias para não repassar a terra para as filhas. A terra configura-se na condição de "acessório" ou como uma forma complementar ao enxoval ou aos estudos. Nos casos em que as filhas ganham terras, a forma de recebimento é, sobretudo, "simbólica", ou seja, os pais reconhecem o direito das filhas em receber terra, mas a substituem por valores monetários para evitar a fragmentação da área. Em outras situações, as filhas até têm acesso a terra, mas ficam "moralmente" condicionadas a executar a venda da área ao irmão sucessor, seja por elas ou pelo marido, facilitando ao sucessor a reintegração da área do estabelecimento familiar.

Nesse sentido, apesar dos agricultores permitirem às filhas receber terras, a chefia ou a sucessão do estabelecimento não lhes é assegurado em nenhum dos casos em que há filhos homens. Mesmo quando recebem terras, a expectativa da venda para o irmão não possibilita o uso na atividade agrícola ou a retirada do seu sustento daquela área. $A$ única situação em que as filhas permanecem como sucessoras dos estabelecimentos é nos casos em que são filhas únicas; não havendo um irmão para "disputar" a sucessão, o estabelecimento é repassado a uma das filhas ou a filha (quando tiver apenas uma).

O que se observa é que, apesar das mudanças em torno da questão sucessória na agricultura familiar, especialmente pela desistência de filhos e filhas em permanecer no meio rural, as situações de compensação das filhas vem se mantendo ao longo das gerações, ou seja, não recebem terras.

R. Inter. Interdisc. INTERthesis, Florianópolis, v.7, n.1, p. 222-141, jan./jul. 2010 


\section{REFERÊNCIAS}

ABRAMOVAY, R. Paradigmas do capitalismo agrário em questão. São Paulo: Hucitec, ANPOCS; Campinas: Editora da Unicamp, 1992.

ABRAMOVAY, R. Agricultura familiar e serviço público: novos desafios a extensão rural. Brasília. Cadernos de Ciência \& Tecnologia, Brasília, v. 15, n.1, p.132-152, jan/abr. 1998. Disponível em: <http://webnotes.sct.embrapa.br/pdf/cct/v15/cc15n106.pdf>. Acesso em: 03 jan. 2007.

ALMEIDA, M. W. B. de. Redescobrindo a família rural. Revista Brasileira de Ciências Sociais, São Paulo, v.1, n. 1, p. 66-83, jun. 1986.

BRASIL. Ministério do Desenvolvimento Agrário. Secretária da Agricultura Familiar. Resoluções do PRONAF. MDA/SAF, 2008. Disponível em:

http://www.mda.gov.br/saf/index.php?sccid=1862. Acesso em: 25 fev. 2009.

BRUMER, A. Qual a "vocação" produtiva da agricultura familiar? Globalização, produção familiar e trabalho na agricultura gaúcha. In: TEDESCO, J. C. (Org.). Agricultura Familiar: realidades e perspectivas. 3. ed. Passo Fundo: Editora da UPF, 2001. p. 223254.

CARNEIRO, M. J. Camponeses, agricultores e pluriatividade. Rio de Janeiro: Contra Capa, 1998.

CARNEIRO, M. J. Herança e gênero entre agricultores rurais. Revista Estudos Feministas, Florianópolis, v. 9, n. 2, p. 22-55, jun./dez. 2001.

CHAMPAGNE, P. La reproduction de l'identité. Actes de la Recherche en Sciences Sociales, Paris, n. 65, p. 41-64, nov. 1986a.

CHAMPAGNE, P. Elargissement de l'espace social et crise de l'identité paysanne. Cahiers d'Economie et Sociologie Rurales, Paris, n.3, p.73-89, dez. 1986b.

DEERE, C.; LÉON, M. O empoderamento da mulher: direitos à terra e direitos a propriedade na América Latina. Porto Alegre: Editora da UFRGS, 2002.

R. Inter. Interdisc. INTERthesis, Florianópolis, v.7, n.1, p. 222-141, jan./jul. 2010 
GASSON, R.; ERRINGTON, A. The farm family business. Wallingford: Cab International, 1993.

MARIN, J. O. B. Crianças do trabalho. Goiânia: Editora da UFG, Brasília: Plano, 2005.

NOVO CÓDIGO CIVIL - Lei n 10.406, de 10.01.2002, DOU 1 de 11.01.2002. Disponível em:

<http://www.senado.gov.br/web/senador/alvarodi/b menu esquerdo/4 biblioteca virtual/N ovo codigo civil.pdf>. Acesso em: 01 abr. 2008.

PAULILO, M. I. Trabalho familiar: uma categoria esquecida de análise. Revista Estudos Feministas, Florianópolis, v.12, n.1, p. 229-252, jan./abr. 2004.

SANTOS, J. V. T. dos. Colonos do vinho: estudo sobre a subordinação do trabalho camponês ao capital. 2.ed. São Paulo: Hucitec, 1984.

SEYFERTH, G. Herança e estrutura familiar. Boletim do Museu Nacional, Rio de Janeiro, n.52, p. 1-27, 1985.

SPANEVELLO, R. M. A dinâmica sucessória na agricultura familiar. 2008. 236f. Tese (Doutorado em Desenvolvimento Rural) Programa de Pós - Graduação em Desenvolvimento Rural, Universidade Federal do Rio Grande do Sul, 2008.

STROPASOLAS, V. O mundo rural no horizonte dos jovens: o caso dos filhos (as) de agricultores familiares de Ouro/SC. 2002. Tese (Doutorado em Ciências Humanas) Programa de Pós- Graduação Interdisciplinar em Ciências Humanas, Universidade Federal de Santa Catarina, Florianópolis. 2002.

STROPASOLAS, V. O valor (do) casamento na agricultura familiar. Revista Estudos Feministas, Florianópolis, v.12, n.1, p.253-267, jan./abr. 2004.

TEDESCO, J, C. Terra, trabalho e família: racionalidade produtiva e ethos camponês. Passo Fundo: Editora da UPF, 1999.

WANDERLEY, M. N. Raízes históricas do campesinato brasileiro. In: TEDESCO, J. C. (Org.) Agricultura familiar: realidade e perspectivas. 3.ed. Passo Fundo: Editora da UPF, 2001. p. 21-55.

R. Inter. Interdisc. INTERthesis, Florianópolis, v.7, n.1, p. 222-141, jan./jul. 2010 
WOORTMANN, E. Herdeiros, parentes e compadres: colonos do Sul e sitiantes no Nordeste. São Paulo: Hucitec; Brasília: Editora da UNB, 1995.

WOORTMANN, E; WOORTMANN, K. O trabalho da terra: a lógica e a simbólica da lavoura camponesa. Brasília: Editora da UNB, 1997.

Artigo:

Recebido em: 12/08/2009

Aceito em: 04/05/2010

R. Inter. Interdisc. INTERthesis, Florianópolis, v.7, n.1, p. 222-141, jan./jul. 2010 